\title{
Ethnic, Racial and Cultural Identity and Perceived Benefits and Barriers Related to Genetic Testing for Breast Cancer among At-Risk Women of African Descent in New York City
}

\author{
K.M. Sussner ${ }^{a} \quad$ T.A. Edwards ${ }^{a} \quad$ H.S. Thompson ${ }^{a}$ b $\quad$ L. Jandorfa N.O. Kwate ${ }^{c}$ \\ A. Forman ${ }^{\text {e K. Brown }}{ }^{d} \quad$ N. Kapil-Paira $\quad$ D.H. Bovbjerg ${ }^{f} \quad$ M.D. Schwartz ${ }^{g}$ \\ H.B. Valdimarsdottir ${ }^{a, h}$
}

\begin{abstract}
${ }^{a}$ Mount Sinai School of Medicine, Department of Oncological Sciences, Division of Cancer Prevention and Control, New York, N.Y., ${ }^{b}$ Wayne State University School of Medicine, Department of Oncology, Population Studies and Disparities Research, Karmanos Cancer Institute, Detroit, Mich., 'C Columbia University Mailman School of Public Health, Department of Sociomedical Sciences, and d Mount Sinai School of Medicine, Department of Genetics and Genomic Sciences, Division of Medical Genetics, New York, N.Y., e Fox Chase Cancer Center, Cancer Prevention and Control, Philadelphia, Pa., and fUniversity of Pittsburgh Cancer Institute and Department of Psychiatry, University of Pittsburgh, Pittsburgh, Pa., ${ }^{9}$ Lombardi Comprehensive Cancer Center, Georgetown University, Washington, DC., USA; h University of Iceland, Department of Psychology, Reykjavik, Iceland
\end{abstract}

\section{Key Words}

Breast cancer · Cultural identity · Ethnic identity .

Genetic testing $\cdot$ Racial identity

\begin{abstract}
Background: Due to disparities in the use of genetic services, there has been growing interest in examining beliefs and attitudes related to genetic testing for breast and/or ovarian cancer risk among women of African descent. However, to date, few studies have addressed critical cultural variations among this minority group and their influence on such beliefs and attitudes. Methods: We assessed ethnic, racial and cultural identity and examined their relationships with perceived benefits and barriers related to genetic testing for cancer risk in a sample of 160 women of African descent (49\% self-identified African American, 39\% Black-West Indian/ Caribbean, 12\% Black-Other) who met genetic risk criteria and were participating in a larger longitudinal study including the opportunity for free genetic counseling and testing
\end{abstract}

in New York City. All participants completed the following previously validated measures: (a) the multi-group ethnic identity measure (including ethnic search and affirmation subscales) and other-group orientation for ethnic identity, (b) centrality to assess racial identity, and (c) Africentrism to measure cultural identity. Perceived benefits and barriers related to genetic testing included: (1) pros/advantages (including family-related pros), (2) cons/disadvantages (including family-related cons, stigma and confidentiality concerns), and (3) concerns about abuses of genetic testing. Results: In multivariate analyses, several ethnic identity elements showed significant, largely positive relationships to perceived benefits about genetic testing for breast and/or ovarian cancer risk, the exception being ethnic search, which was positively associated with cons/disadvantages, in general, and family-related cons/disadvantages. Racial identity (centrality) showed a significant association with confidentiality concerns. Cultural identity (Africentrism) was not related to perceived benefits and/or barriers. Conclusions: Ethnic and racial identity may influence perceived benefits and

\section{KARGER}

(C) 2011 S. Karger AG, Basel

Fax +41613061234 E-Mail karger@karger.ch www.karger.com
Accessible online at: www.karger.com/phg
Dr. Katarina M. Sussner

Department of Oncological Sciences, Division of Cancer Prevention and Contro Mount Sinai School of Medicine

1425 Madison Avenue, Box 1130, New York, NY 10029 (USA)

Tel. +1 212659 5555, E-Mail katarina.sussner@mssm.edu 
barriers related to genetic testing for breast and/or ovarian cancer risk among at-risk women of African descent. Genetic counseling services may want to take into account these factors in the creation of culturally-appropriate services which best meet the needs of this heterogenous population.

Copyright $\odot 2011$ S. Karger AG, Base

\section{Introduction}

Family history is one of the strongest predictors of a woman's lifetime risk of developing breast and/or ovarian cancer, with individuals carrying mutations in $B R C A 1$ or $B R C A 2$ genes having between a $40-66 \%$ cumulative risk of developing breast cancer and a 13-46\% cumulative risk of developing ovarian cancer [1]. Despite increasing recognition of the importance of genetic risk information and availability of genetic counseling and testing for BRCA1/2 mutations [2], numerous studies show that high risk African-American women may substantially underuse genetic services [2-8]. Indeed, White women have been reported to be 5 times more likely to undergo genetic counseling for $B R C A 1 / 2$ testing compared to African-American women [6]. Such findings are alarming, given that African-American women have higher rates of early-onset breast cancer and higher mortality rates compared to other groups $[9,10]$.

Research suggests that racial disparities in genetic counseling and testing use are partly attributable to limited knowledge $[2,11-13]$ as well as differences in perceived testing benefits and barriers related to BRCA genetic testing among African-American women. Perceived benefits previously shown to be rated higher by AfricanAmerican women include: the opportunity for better informed screening and treatment decisions, the potential prevention of cancer and/or cancer recurrence, determination of family members' risks as well as personal reassurance and reduction of uncertainty via genetic testing $[2,11,13,14]$. Perceived barriers have included concerns about testing abuses, potential stigmatization that may accompany learning mutation status and confidentiality concerns $[11,15]$. These perceived barriers may be especially applicable for individuals of African descent given a long social history in the U.S. including the eugenics movement which misused genetic information to falsely warrant the assumed superiority or inferiority of specific racial/ethnic groups to others, promoting discrimination and unfavorable racial stereotypes [15-18]. Yet surprisingly, despite calls for the creation of culturally-sensitive health interventions for genetics services [8, 18-21], very few studies have examined cultural variables as they relate to genetic testing beliefs and attitudes among diverse groups of women of African descent to promote more culturally-sensitive care by genetic risk professionals [15]. Combined with an ever-growing body of research that underscores the importance of examining the heterogeneity of the African experience as it relates to health [21-25], there is clearly a need for research that examines such culturally-related factors which may vary at the individual level among women of African descent and their possible influence on beliefs and attitudes about genetic testing for cancer risk. The few published studies to date have demonstrated significant associations with perceived advantages and disadvantages of genetic testing among women of African descent, with regard to: nativity [26], temporal orientation [27] and medical mistrust $[15,28]$ as well as have shown more fatalistic beliefs and future orientation among genetic test accepters compared to decliners [29]. These findings suggest that other ethnic, racial and cultural identity factors may also influence culturally relevant attitudes about genetic testing in this group. Furthermore, the evolving field of multicultural genetic counseling has recently made calls for the incorporation of the client's psychological view of his/her racial and cultural group as the main indicators of culture over racial phenotype [30], underscoring the importance of studies to determine the influence of these factors on beliefs and attitudes about genetic services. Better understanding of how ethnic, racial and cultural identity factors influence benefits and barriers to genetic testing will help inform the development of culturally-sensitive interventions for diverse groups of women of African descent [8, 18, 20, 21] and ultimately contribute to more culturally competent care.

The purpose of this cross-sectional secondary analysis was to explore the influences of ethnic, racial and cultural identity on perceived benefits and barriers related to genetic testing for breast and/or ovarian cancer risk among at-risk women of African descent in New York City. We hypothesize that these aspects of identity will be differentially related to perceived benefits and barriers to genetic testing for cancer risk among at-risk individuals of African descent. This research is guided by an overarching sociocultural perspective which emphasizes the role of membership in a specific group and its influence over daily life [31, 32] as well as incorporates both psychological identity theory and race-based cultural typology. Identity theory posits that the choices individuals make are largely a function of the extent to which those choices are related to a personally relevant role-identity $[33,34]$. Given that the concepts of ethnic, racial and cultural 
identity are closely intertwined within this larger identity theory, we chose to examine all 3 components in this study. Ethnic identity theory stems from literature in psychology supporting the view that it is more informative to explore psychological aspects of ethnicity compared to self-described racial group labels, although the terms of race and ethnicity have often been used interchangeably $[35,36]$. In fact, ethnicity is considered here different than race, with ethnicity focused on perceived common ancestry [37], thereby theoretically allowing people of the same race to have different ethnicities based on this ancestry. Included under the umbrella of ethnic identity is often other-group orientation, as research shows that understanding the attitudes African Americans have toward other ethnic and cultural groups is a necessary component to understanding African-American ethnicity [36]. Racial identity theory accepts a race-based cultural typology, in which identity is understood as a function of racialized experiences based on the assumption that 'experience of belonging to a racial group transcends all other experiences' [30, 38]. Other research suggests that although phenotypical traits are a salient aspect of identity for individuals of African descent, racial identity is closely aligned with cultural identity rooted in an Afrocentric worldview paradigm [36, 39]. Furthermore, although ethnic identity measures aim to examine the identity component of ethnicity, such measures may not be specific to Africentric cultural values, underscoring the need for distinct cultural identity measures, such as Africentrism [40]. These identity factors may have particular relevance in metropolitan areas such as New York City where individuals of African descent have diverse cultural backgrounds and non-Hispanic Caribbean immigrants make up $21 \%$ of the foreign-born population [41].

\section{Methods}

\section{Study Setting and Population}

We conducted a cross-sectional secondary analysis of baseline information available on 160 women of African descent from a larger randomized control trial examining the psychosocial impact of standard genetic counseling versus culturally-tailored genetic counseling in women at increased risk of breast and/or ovarian cancer (see previously published cross-sectional results [26, 27]). Participants in the original longitudinal parent study were recruited in the greater New York City area through an existing study on biobehavioral factors and breast cancer risk, through genetic counselors in the clinical service and via community outreach, including physician referral and participant initiation. Most participants were recruited following women's initiation of contact with the study team via physician referral or community outreach, and therefore, the total number of women referred to the study is unknown. A trained research assistant or genetic counselor explained the study to all interested potential participants and completed a family history form to determine eligibility based on family history suggestive of breast and/or ovarian cancer. Eligibility criteria included: women who self-identified as being of African descent, age 18 or older, English speaking, able to provide consent, had not previously undergone genetic counseling or testing for hereditary breast and/or ovarian cancer, and had a family history suggestive of the hereditary breast-ovarian cancer syndrome. Family history criteria were developed for the study in accordance with current clinical guidelines for identifying individuals at increased risk for hereditary breast-ovarian cancer. For this study, women were considered eligible if they met at least a $10 \%$ mutation probability by any of one of the 3 commonly used BRCA1/2 mutation probability models (BRCAPro, Penn and Myriad) [42-44]. Pregnant women were excluded, as pregnancy-related distress could influence concerns about genetic testing for breast and/or ovarian cancer. Consent forms were mailed to all eligible women who met the study criteria. All participants completed a baseline survey through a telephone interview and were then given the option of receiving free genetic services for $B R C A 1 / 2$, including being randomly assigned to either standard genetic counseling or culturally-tailored genetic counseling. Participants were given the option to obtain genetic testing after counseling. Participants were then followed up at 1 month post-counseling to determine their decision-making related to $B R C A 1 / 2$ genetic testing. For the cross-sectional secondary data analysis conducted in this study, we report only information obtained from the baseline data collected prior to randomization to genetic counseling, including information about socio-demographics; ethnic, racial, and cultural identity; breast/ovarian cancer, personal and family history; and attitudes and beliefs about $B R C A$ genetic testing. Approval was obtained through Mount Sinai's Institutional Review Board for all study protocols. Participants received no monetary payment, however, genetic counseling and testing were provided at no cost.

\section{Measures}

Specific measures for ethnic, racial and cultural identity are outlined in table 1 and described here as follows:

\section{Ethnic Identity}

(a) The Multi-Group Ethnic Identity Measure. The multi-group ethnic identity measure (MEIM), originally developed by Phinney [35], has been used in dozens of studies as a universal measure of ethnic identity across a range of ethnic groups, with consistently strong reliability. This 12 -item scale includes 2 factors: ethnic identity search (hereafter referred to as ethnic search) and affirmation, belonging and commitment (hereafter referred to as ethnic affirmation), with the preferred scoring using the mean of the 12-items for a total score as well as the mean of the 5 items for search and the 7 items for affirmation as subscale scores. The range of scores follows a Likert-type scale from 1-4 (strongly disagree to strongly agree), with higher scores indicating more positive ethnic identity. The MEIM total score showed strong internal reliability in this study $(\alpha=0.88)$.

Ethnic Search Subscale. The mean ethnic search score is comprised of 5 items from the MEIM related to time spent trying to 
Table 1. Description of ethnic, racial and cultural identity predictors

\begin{tabular}{|c|c|}
\hline Items included & $\begin{array}{l}\text { Internal } \\
\text { reliability, } \\
\text { alpha }\end{array}$ \\
\hline \multicolumn{2}{|l|}{ Ethnic identity } \\
\hline \multicolumn{2}{|l|}{ MEIM Total (12 items) } \\
\hline \multicolumn{2}{|c|}{ Ethnic Search Subscale (5 items) } \\
\hline $\begin{array}{l}\text { - I have spent time trying to find out more about my own ethnic group, such as its hi } \\
\text { - I am active in organizations or social groups that include mostly members of my or } \\
\text { - I think a lot about how my life will be affected by my ethnic group membership } \\
\text { - In order to learn more about my ethnic background, I have often talked to other pe } \\
\text { - I participate in cultural practices of my own group, such as special food, music, or }\end{array}$ & \\
\hline Ethic affirmation subscale (7 items) & 0.86 \\
\hline \multicolumn{2}{|l|}{ - I have a clear sense of my ethnic background and what it means for me } \\
\hline \multicolumn{2}{|l|}{ - I am happy that I am a member of the group I belong to } \\
\hline \multicolumn{2}{|l|}{ - I have a strong sense of belonging to my ethnic group } \\
\hline \multicolumn{2}{|c|}{ - I understand pretty well what my ethnic group membership means to me, in terms of how to relate to my own group and other groups } \\
\hline \multicolumn{2}{|c|}{ - I have a lot of pride in my ethnic group and its accomplishments } \\
\hline \multicolumn{2}{|l|}{ - I feel a strong attachment towards my own ethnic group } \\
\hline \multicolumn{2}{|l|}{ - I feel good about my cultural or ethnic background } \\
\hline Other-Group Orientation Scale (6 items) & 0.67 \\
\hline \multicolumn{2}{|l|}{ - I like meeting and getting to know people from ethnic groups other than my own } \\
\hline \multicolumn{2}{|l|}{$\begin{array}{l}\text { - I sometimes feel it would be better if different ethnic groups didn't try to mix together } \\
\text { - I often spend time with people from ethnic groups other than my own }\end{array}$} \\
\hline \multicolumn{2}{|l|}{$\begin{array}{l}\text { - I often spend time with people from ethnic groups other than my own } \\
\text { - I don't try to become friends with people from other ethnic groups }\end{array}$} \\
\hline - I don't try to become friends with people from other ethnic groups & \\
\hline \multicolumn{2}{|l|}{$\begin{array}{l}\text { - I am involved in activities with people from other ethnic groups } \\
\text { - I enjoy being around people from ethnic groups other than my own }\end{array}$} \\
\hline \multicolumn{2}{|l|}{ - I enjoy being around people from ethnic groups other than my own } \\
\hline
\end{tabular}

Racial identity

Centrality Subscale (8 items)

- Overall, being Black has very little to do with how I feel about myself

- In general, being Black is an important part of my self-image

- My destiny is tied to the destiny of other Black people

- Being Black is unimportant to my sense of what kind of person I am

- I have a strong sense of belonging to Black people

- I have a strong attachment to other Black people

- Being Black is an important reflection of who I am

- Being Black is not a major factor in my social relationships

Cultural identity

Africentrism (15 items)

- Black people should make their community better than it was when they found it

- The problems of other Blacks are their problems, not mine

- The unity of the African race is very important to me

- I am more concerned with reaching my own goals than with working for the Black community

- I have very little faith in Black people

- I owe something to Black people who suffered before me

- Black people need to stop worrying so much about 'the community' and take care of their own needs

- I am doing a lot to improve my neighborhood

- The success I have had is mainly because of me, not anyone else

- I have more confidence in White professionals, like doctors and teachers, than in Black professionals

- Black people should build and maintain their own communities

- I must do all I can to restore Black people to their position of respect in the world

- I make it a point to shop at Black businesses and use Black-owned services

- It hurts me when I see another Black person discriminated against

- It is important that Black people decide for themselves what to be called and what their needs are 
find out about one's ethnic group, activity in organizations and social groups related to one's ethnic group, time spent thinking about ethnic group membership, and extent of participation in cultural practices unique to one's ethnic group. These 5 items demonstrated good internal reliability in this study $(\alpha=0.76)$.

Ethnic Affirmation Subscale. The mean ethnic affirmation score is computed with 7 items from the MEIM including sense of one's ethnic group and meaning, happiness, belonging, pride and attachment towards one's own ethnic group. This subscale was highly reliable $(\alpha=0.86)$.

(b) Other-Group Orientation. The other-group orientation scale is a distinct identity scale which was developed in tandem with the original MEIM [35] and is often used in conjunction with the MEIM to assess relationship to ethnic groups different than one's own. The scale includes 6 items scored on a Likert-type scale 1-4 (strongly disagree to strongly agree), measuring how often one meets and gets to know people from other ethnic groups, participates in activities with people from other groups as well as how one feels about people from different ethnic groups spending time together. This scale demonstrated adequate internal reliability $(\alpha=0.67)$.

\section{Racial Identity}

(a) Centrality. The centrality subscale of the Multidimensional Inventory of Black Identity is a well-known validated measure for assessing African-American racial identity [34]. This inventory measures the extent to which race is a core part of an individual's self-concept. The Centrality subscale of the Multidimensional Inventory of Black Identity consists of 8 items on a Likerttype scale ranging from strongly disagree to strongly agree (1-4). The Centrality subscale demonstrated good internal reliability for our sample $(\alpha=0.79)$.

\section{Cultural Identity}

(a) Africentrism. The Africentrism scale examines the cultural component of ethnicity, by assessing Africentric cultural values, traditions and behavioral beliefs [40]. This previously validated 15 -item scale is based on the principles of the African cultural celebration of Kwanzaa, called the Nguzo Sabo, and includes measures of unity, self-determination, collective work and responsibility, cooperative economics, purpose, creativity, and faith. All items are measured on a 1-4 Likert-type scale (strongly disagree to strongly agree), with a higher score indicating more endorsement of Afrocentric values and behaviors. The internal reliability of the Africentrism scale was considered good for our sample $(\alpha=0.76)$.

\section{Covariates}

Sociodemographic Factors. Sociodemographic factors assessed participants' age, self-identified race/ethnicity, education, income, and insurance status.

Breast and/or Ovarian Cancer History. Information about participants' personal diagnosis and family history of breast and/or ovarian cancer was also obtained.

\section{Outcomes}

The original baseline interview examined in this study included a one-paragraph description in layman's terms of the hereditary basis of breast and ovarian cancer and how genetic tests may be used to determine which family members have inherited a genetic mutation. Participants were asked how much they agreed or disagreed with a series of statements about potential perceived benefits and barriers related to genetic testing, knowing that a blood test for inherited breast cancer is currently available. In this study, we examined the following perceived benefits and barriers related to genetic testing as outlined in table 2, including: (1) pros/ advantages (including family-related pros subscale) of genetic testing, (2) cons/disadvantages (including family-related cons, stigma and confidentiality concerns subscales) of genetic testing, and (3) concerns about abuses of genetic testing. These outcomes have been previously created and validated for use in AfricanAmerican women as they relate to $B R C A$ testing $[8,14,45,46]$. All questions were measured on a 5-point Likert-type scale (strongly disagree to strongly agree), with total scores computed by summing individual questions and taking the average (range $=1-5$ ). Internal reliability of all scales was good (range $=0.67-0.84$ ).

\section{Analytic Plan}

We computed basic descriptive statistics, as reported in table 3. Initial univariate linear regression analyses examined each predictor (ethnic, racial and cultural identity) and covariate individually and determined its association with study outcomes. We also computed individual correlations among the identity measures. In cases of missing data, we omitted those individuals from analysis. We developed multivariate linear regression models separately for each study outcome with the following steps: We explored all significant variables $(p<0.10)$ in univariate analyses as potential covariates for inclusion in the candidate short list for multivariate models. We conducted a forward selection test as the automatic statistical procedure of choice to control for potential problems of multicollinearity among variables in the models. Due to a relatively small sample size, we chose a level of significance of $\mathrm{p}<0.10$ as most appropriate for determining initial entry into the forward selection test. We then included variables significant from the forward selection test in final multivariate linear regression models. We added all other covariates independently associated with the outcomes one by one to test for potential confounding. We considered any such covariates producing a change of at least $20 \%$ in the Beta weights of predictors already in the model (from forward selection) as potential confounders and included them in final models. We also included any theoretically critical sociodemographic variables (i.e. age, personal and family history of breast and/or ovarian cancer). We used a level of $p<0.05$ to determine overall statistical significance of variables in the final model. We used an $\mathrm{R}^{2}$ test to determine the percentage of the variability explained by the final multivariable linear regression model. All statistical procedures used SAS software package v.9.1.3.

\section{Results}

\section{Sample Characteristics}

Sample characteristics are presented in table 3, where the total sample size (n) refers to number of participants responding to individual questionnaire items and changes based upon mode of questionnaire administration, interviewer versus self-administered. As such, since not all participants completed all phases of these questionnaires, 
Table 2. Description of outcomes: perceived benefits and barriers related to genetic testing for cancer risk

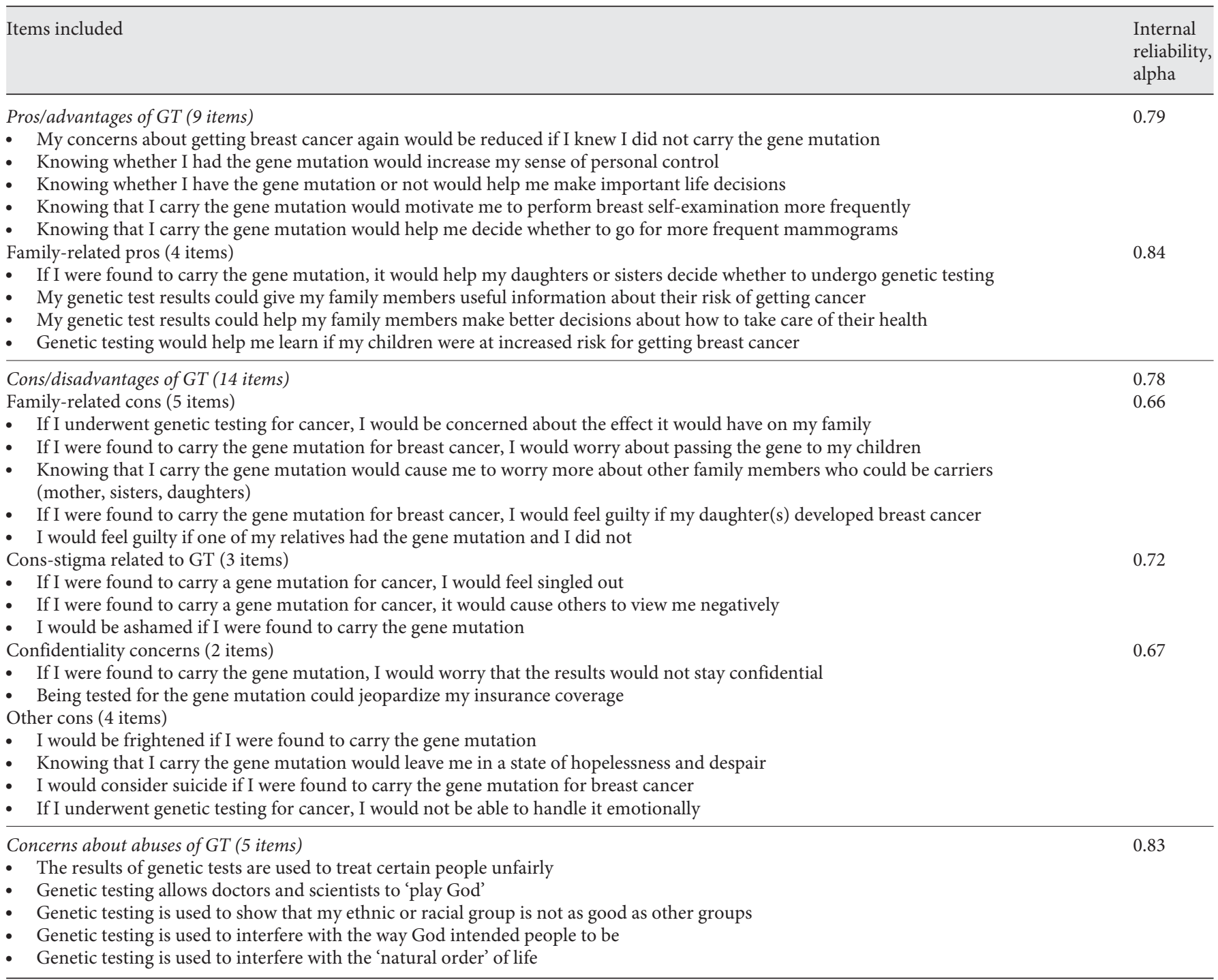

there are instances of missing data for some participants. The mean age of participants in the sample was 45.3 years $(\mathrm{SD}=9.5 ; \min .=22$; $\max .=79)$. Close to half of participants in the sample self-identified themselves as Black/African American (49.4\%), more than a third identified as Black/West Indian/Carribbean (39.4\%), with the others (11.2\%) identifying as Black-Other (Black-African, BlackMultiethnic, Black-Other-Hispanic). The majority (71\%) had more than a high school diploma, made more than USD 20,000/year (71\%), and were insured (84\%). Most participants had a personal history of breast and/or ovarian cancer (64\%), while the majority had a family history of breast and/or ovarian cancer (76\%). Meanwhile, almost half of participants reported both a personal and family history of breast and/or ovarian cancer (41\%). The majority of participants completed free genetic counseling for breast and/or ovarian cancer risk offered as part of the longitudinal study, with $88 \%$ completing the first session and $84 \%$ completing the second session. The majority of participants also completed genetic testing for breast/ovarian cancer risk (84\%). In terms of the identity predictors of interest, the mean scores for ethnic identity were: 3.0 (SD = $0.4)$ for total MEIM, $2.7(\mathrm{SD}=0.6)$ for the ethnic search subscale, $3.3(\mathrm{SD}=0.4)$ for the ethnic affirmation subscale and $3.2(\mathrm{SD}=0.4)$ on the other-group orientation scale. For racial identity, the mean score for the centrality subscale 
Table 3. Baseline statistics: ethnic, racial and cultural identity predictors and perceived benefits and barriers related to genetic testing (GT) for cancer risk

\begin{tabular}{|c|c|c|c|}
\hline Predictor variables & Sample, mean (SD) & Range & $\mathrm{n}(\%)^{*}$ \\
\hline \multicolumn{4}{|l|}{ Ethnic, racial and cultural identity predictors ${ }^{* *}$} \\
\hline \multicolumn{4}{|l|}{ Ethnic identity } \\
\hline Total MEIM score (high = more positive ethnic identity) & $3.0(0.4)$ & $1.9,3.9$ & 140 \\
\hline Total ethnic search score & $2.7(0.6)$ & $1.0,4.0$ & 140 \\
\hline Total ethnic affirmation score & $3.3(0.4)$ & $1.0,4.0$ & 140 \\
\hline Other-group orientation scale (high $=$ more other-group orientation) & $3.2(0.4)$ & $2.2,4.0$ & 140 \\
\hline \multicolumn{4}{|l|}{ Racial identity } \\
\hline Centrality subscale (high = more centrality) & $2.6(0.5)$ & $1.1,4.0$ & 140 \\
\hline \multicolumn{4}{|l|}{ Cultural identity } \\
\hline Total Africentrism score (high = more Africentrism) & $2.9(0.3)$ & $2.3,3.9$ & 139 \\
\hline \multicolumn{4}{|l|}{ Covariates } \\
\hline \multicolumn{4}{|l|}{ Sociodemographics } \\
\hline Age & $45.3(9.5)$ & 22,79 & 160 \\
\hline \multicolumn{4}{|l|}{ Self-identified race/ethnicity } \\
\hline Black/African American & $\mathrm{n} / \mathrm{a}$ & $\mathrm{n} / \mathrm{a}$ & $79(49.4)$ \\
\hline Black-West Indian/Caribbean & $\mathrm{n} / \mathrm{a}$ & $\mathrm{n} / \mathrm{a}$ & $63(39.4)$ \\
\hline Black-Other & $\mathrm{n} / \mathrm{a}$ & $\mathrm{n} / \mathrm{a}$ & $18(11.2)$ \\
\hline \multicolumn{4}{|l|}{ Education } \\
\hline$\leq$ High school diploma & $\mathrm{n} / \mathrm{a}$ & $\mathrm{n} / \mathrm{a}$ & $46(29)$ \\
\hline$>$ High school diploma & $\mathrm{n} / \mathrm{a}$ & $\mathrm{n} / \mathrm{a}$ & $114(71)$ \\
\hline \multicolumn{4}{|l|}{ Income USD } \\
\hline$\leq 19,999 /$ year & $\mathrm{n} / \mathrm{a}$ & $\mathrm{n} / \mathrm{a}$ & $44(29)$ \\
\hline$\geq 20,000 /$ year & $\mathrm{n} / \mathrm{a}$ & $\mathrm{n} / \mathrm{a}$ & $108(71)$ \\
\hline \multicolumn{4}{|l|}{ Insurance status } \\
\hline Insured (public \& private) & $\mathrm{n} / \mathrm{a}$ & $\mathrm{n} / \mathrm{a}$ & $135(84)$ \\
\hline Non-insured & $\mathrm{n} / \mathrm{a}$ & $\mathrm{n} / \mathrm{a}$ & $25(16)$ \\
\hline \multicolumn{4}{|l|}{ Cancer history } \\
\hline \multicolumn{4}{|l|}{ Personal history of breast/ovarian cancer } \\
\hline Yes & $\mathrm{n} / \mathrm{a}$ & $\mathrm{n} / \mathrm{a}$ & $102(64)$ \\
\hline No & $\mathrm{n} / \mathrm{a}$ & $\mathrm{n} / \mathrm{a}$ & $58(36)$ \\
\hline \multicolumn{4}{|l|}{ Family history of breast/ovarian cancer } \\
\hline Yes & $\mathrm{n} / \mathrm{a}$ & $\mathrm{n} / \mathrm{a}$ & $121(76)$ \\
\hline No & $\mathrm{n} / \mathrm{a}$ & $\mathrm{n} / \mathrm{a}$ & $39(24)$ \\
\hline \multicolumn{4}{|l|}{ Both personal/family history breast/ovarian } \\
\hline Yes & $\mathrm{n} / \mathrm{a}$ & $\mathrm{n} / \mathrm{a}$ & $66(41)$ \\
\hline No & $\mathrm{n} / \mathrm{a}$ & $\mathrm{n} / \mathrm{a}$ & $94(59)$ \\
\hline \multirow{2}{*}{\multicolumn{4}{|c|}{ Participation in free genetic counseling (GC) as part of larger study }} \\
\hline \multicolumn{2}{|l|}{ First GC session status } & & \\
\hline Completed & $\mathrm{n} / \mathrm{a}$ & $\mathrm{n} / \mathrm{a}$ & $141(88)$ \\
\hline Cancelled/passive refuser & $\mathrm{n} / \mathrm{a}$ & $\mathrm{n} / \mathrm{a}$ & $10(6)$ \\
\hline Did not attend & $\mathrm{n} / \mathrm{a}$ & $\mathrm{n} / \mathrm{a}$ & $9(6)$ \\
\hline Genetic testing completed & $\mathrm{n} / \mathrm{a}$ & $\mathrm{n} / \mathrm{a}$ & $134(84)$ \\
\hline \multicolumn{4}{|l|}{ Second GC session status } \\
\hline Completed & $\mathrm{n} / \mathrm{a}$ & $\mathrm{n} / \mathrm{a}$ & $128(80)$ \\
\hline Cancelled/passive refuser & $\mathrm{n} / \mathrm{a}$ & $\mathrm{n} / \mathrm{a}$ & $2(1)$ \\
\hline Did not attend & $\mathrm{n} / \mathrm{a}$ & $\mathrm{n} / \mathrm{a}$ & $30(19)$ \\
\hline \multicolumn{4}{|l|}{ Outcome variables: perceived benefits and barriers related to GT for cancer risk } \\
\hline Pros/advantages of GT (9 items) & $4.2(0.5)$ & $2.8,5.0$ & 160 \\
\hline Family-related pros of GT (4 items) & $4.4(0.5)$ & $2.0,5.0$ & 159 \\
\hline Cons/disadvantages of GT (14 items) & $2.4(0.4)$ & $1.3,3.8$ & 160 \\
\hline Family-related cons/disadvantages of GT ( 5 items) & $3.2(0.6)$ & $1.4,4.8$ & 160 \\
\hline Stigma related to GT (3 items) & $1.8(0.6)$ & $1.0,4.0$ & 160 \\
\hline Confidentiality concerns related to GT ( 2 items) & $2.2(0.8)$ & $1.0,5.0$ & 160 \\
\hline Concerns about abuses of GT ( 5 items) & $1.9(0.6)$ & $1.0,3.4$ & 158 \\
\hline
\end{tabular}

* Where the total sample size (n), referring to number of participants responding to individual questionnaire items changes based upon mode of questionnaire administration, interviewer vs. self-administrated. ${ }^{*}$ Where there was strong collinearity $(0.18 \leq \mathrm{r} \leq 0.90 ; 0.03 \leq \mathrm{p} \leq 0.0001)$ found between all of these identity measures with the exception of the relationship between centrality and other group orientation, which was not significant $(\mathrm{r}=0.08 ; \mathrm{p}=0.33)$. 
Table 4. Significant unadjusted predictor estimates of perceived benefits and barriers related to genetic testing (GT) for cancer risk outcomes

\begin{tabular}{|c|c|c|c|}
\hline $\begin{array}{l}\text { Perceived benefits and } \\
\text { barriers related to GT }\end{array}$ & Significant unadjusted predictors* & $\begin{array}{l}\beta \text { coefficient/ } \\
\text { parameter estimate (SE) }\end{array}$ & $\mathrm{p}$ value \\
\hline \multirow[t]{4}{*}{ Pros/advantages of GT } & MEIM (total) & $0.26(0.09)$ & 0.007 \\
\hline & Ethnic search & $0.17(0.08)$ & 0.03 \\
\hline & Ethnic affirmation & $0.24(0.09)$ & 0.01 \\
\hline & Other-group orientation & $0.27(0.11)$ & 0.01 \\
\hline \multirow[t]{3}{*}{ Family-related pros/advantages of GT } & MEIM (total) & $0.21(0.10)$ & 0.05 \\
\hline & Ethnic affirmation & $0.29(0.10)$ & 0.005 \\
\hline & Other-group orientation & $0.33(0.11)$ & 0.004 \\
\hline Cons/disadvantages GT & Ethnic search & $0.14(0.07)$ & 0.04 \\
\hline Family-related cons & Ethnic search & $0.24(0.10)$ & 0.02 \\
\hline \multirow[t]{3}{*}{ Stigma associated with GT } & Ethnic affirmation & $-0.19(0.11)$ & 0.08 \\
\hline & Other-group orientation & $-0.28(0.13)$ & 0.03 \\
\hline & Age & $0.01(0.005)$ & 0.03 \\
\hline \multirow[t]{5}{*}{ Confidentiality concerns related to GT } & Ethnic affirmation & $-0.33(0.15)$ & 0.04 \\
\hline & Centrality & $0.20(0.13)$ & 0.10 \\
\hline & Income & & \\
\hline & $\begin{array}{l}\leq \text { USD 19,999/year vs. } \geq \text { USD 20,000/year } \\
\text { Education }\end{array}$ & $-0.32(0.15)$ & 0.04 \\
\hline & $\leq$ High school vs. $>$ high school & $-0.24(0.15)$ & 0.10 \\
\hline \multirow{2}{*}{ Concerns about abuses of GT } & Other-group orientation & $-0.27(0.11)$ & 0.02 \\
\hline & Age & $0.009(0.004)$ & 0.04 \\
\hline
\end{tabular}

* Significance level $\mathrm{p} \leq 0.10$.

was $2.6(\mathrm{SD}=0.5)$, while for cultural identity, the mean score for Africentrism was $2.9(\mathrm{SD}=0.3)$. There was strong collinearity $(0.18 \leq \mathrm{r} \leq 0.90 ; 0.03 \leq \mathrm{p}<0.0001)$ found between all of these identity measures with the exception of the relationship between centrality and other group orientation, which was not significant $(r=0.08 ; \mathrm{p}=0.33)$. In terms of the outcome variables of interest, beliefs and attitudes about genetic testing for cancer risk, mean scores were the following: $4.2(\mathrm{SD}=0.5)$ for pros/advantages of genetic testing, $4.4(\mathrm{SD}=0.5)$ for family-related pros, 2.4 $(\mathrm{SD}=0.5)$ for cons/disadvantages of genetic testing, 3.2 $(\mathrm{SD}=0.6)$ for family-related cons/disadvantages, $1.8(\mathrm{SD}=$ $0.6)$ for stigma related to genetic testing, $2.2(\mathrm{SD}=0.8)$ for confidentiality concerns related to genetic testing, and 1.9 $(\mathrm{SD}=0.6)$ for concerns about abuses of genetic testing.

\section{Univariate Results}

Table 4 reports the significant $(\mathrm{p}<0.10)$ unadjusted associations in univarate analysis.

\section{Pros/Advantages of Genetic Testing}

The total MEIM score, including ethnic search and affirmation subscales, as well as other-group orientation, were positively associated with pros/advantages about genetic testing for cancer risk.

(a) Family-Related Pros/Advantages of Genetic Testing. For family-related pros/advantages of genetic testing, the total MEIM including ethnic affirmation, as well as other-group orientation, were positively associated with family-related pros/advantages about genetic testing for cancer risk in univariate analyses.

\section{Cons/Disadvantages of Genetic Testing}

Ethnic search was independently related to cons/disadvantages of genetic testing.

(a) Family-Related Cons/Disadvantages of Genetic Testing. Ethnic search was independently associated with family-related cons/disadvantages.

(b) Stigma Associated with Genetic Testing. Ethnic affirmation and other-group orientation were negatively related to stigma associated with genetic testing in uni- 
variate analyses, while age was positively related to stigma associated with genetic testing.

(c) Confidentiality Concerns Related to Genetic Testing. Ethnic affirmation, income and education were negatively related to confidentiality concerns related to genetic testing, while centrality was positively related to confidentiality concerns.

\section{Concerns about Abuses of Genetic Testing}

Independent associations with concerns about abuses of genetic testing included other-group orientation (negatively related) and age (positively related).

\section{Multivariate Results}

Table 5 displays the final multivariate results for all models which included significant adjusted estimates of perceived benefits and barriers related to genetic testing for cancer risk. In these final models, age, family and personal history of breast cancer were considered theoretically critical (if not otherwise previously entered into the model), as they have been shown to influence breast cancer risk and screening practices, beliefs, attitudes, and concerns about genetic testing in women of African descent $[47,48]$.

\section{Pros/Advantages of Genetic Testing}

In multivariate analysis, results indicated that the total MEIM score was positively related to pros/advantages of genetic testing $(\beta=0.20 ; \mathrm{SE}=0.10 ; \mathrm{p}=0.05)$.

(a) Family-Related Pros/Advantages of Genetic Testing. Ethnic affirmation was positively related to family-related pros/advantages in multivariate analysis $(\beta=0.28$; $\mathrm{SE}=0.10 ; \mathrm{p}=0.007)$.

\section{Cons/Disadvantages of Genetic Testing}

Ethnic search was positively related to cons/disadvantages of genetic testing in multivariate analysis $(\beta=0.14$; $\mathrm{SE}=0.07 ; \mathrm{p}=0.04$ ).

(a) Family-Related Cons/Disadvantages of Genetic Testing. Ethnic search was significantly associated with family-related cons/disadvantages related to genetic testing in multivariate analysis $(\beta=0.24 ; \mathrm{SE}=0.10 ; \mathrm{p}=0.02)$.

(b) Stigma Associated with Genetic Testing. In multivariate analysis, other-group orientation was negatively related to perceived stigma associated with genetic testing $(\beta=-0.28 ; \mathrm{SE}=0.12 ; \mathrm{p}=0.03)$.

(c) Confidentiality Concerns Related to Genetic Testing. There was a negative relationship between ethnic affirmation and confidentiality concerns related to genetic testing ( $\beta=-0.56 ; \mathrm{SE}=0.17 ; \mathrm{p}=0.002)$, while centrality showed a positive relationship $(\beta=0.34 ; \mathrm{SE}=0.14 ; \mathrm{p}=$ 0.01 ). Individuals who made $\leq$ USD $20,000 /$ year were less likely to have confidentiality concerns compared to individuals who made $\geq$ USD 20,000/year $(\beta=-0.42$; $\mathrm{SE}=$ $0.15 ; \mathrm{p}=0.008)$. In addition, individuals with personal history of breast/ovarian cancer $(\beta=0.32 ; \mathrm{SE}=0.15 ; \mathrm{p}=$ 0.03 ) were more likely to have confidentiality concerns compared to those without personal history, although results should be considered cautiously as this variable had not previously been significant in univariate analyses.

\section{Concerns about Abuses of GT}

Other-group orientation was negatively related to concerns about abuses of genetic testing in multivariate analysis $(\beta=-0.29 ; \mathrm{SE}=0.12 ; \mathrm{p}=0.02)$.

\section{Discussion}

Study results reveal that ethnic and racial identities are associated with perceived benefits and barriers related to genetic testing for cancer risk among a diverse sample of at-risk women of African descent. Study results largely demonstrated that having a strong sense of ethnic identity was related to having more positive beliefs and attitudes about genetic testing. Specifically, results indicated a positive association between total MEIM score and pros/advantages of genetic testing as well as for the relationship between ethnic affirmation and family-related pros/advantages. There was also a negative, yet potentially protective relationship found between ethnic affirmation and confidentiality concerns associated with genetic testing as well as for other-group orientation and its relationship to both stigma associated with genetic testing and concerns about abuses of genetic testing. Ethnic search was the only ethnic identity factor measured in this study that demonstrated a negative relationship with beliefs about genetic testing in multivariate analyses, in that individuals with higher ethnic search scores reported more cons/disadvantages and family-related cons/disadvantages of genetic testing. Racial identity assessed in this study via the centrality subscale of the Multidimensional Inventory of Black Identity was related to perceived barriers, as results indicated that women with higher centrality scores reported more confidentiality concerns related to genetic testing. Finally, cultural identity, as measured in this study by Africentrism, showed no significant relationship to perceived benefits or barriers related to genetic testing for cancer risk. 
Table 5. Final multivariate models: significant adjusted predictor estimates of perceived benefits and barriers related to genetic testing (GT) for cancer risk outcomes

\begin{tabular}{|c|c|c|c|c|}
\hline $\begin{array}{l}\text { Perceived benefits and } \\
\text { barriers related to GT }\end{array}$ & Final multivariable model & $\begin{array}{l}\beta \text { coefficient/ } \\
\text { parameter estimate (SE) }\end{array}$ & $\mathrm{p}$ value & $\mathrm{R}^{2}$ \\
\hline Pros/advantages of GT & $\begin{array}{l}\text { MEIM (total) } \\
\text { Other-group orientation } \\
\text { Age } \\
\text { Family history of breast/ovarian cancer } \\
\quad \text { Yes vs. no } \\
\text { Personal history of breast/ovarian cancer } \\
\text { Yes vs. no }\end{array}$ & $\begin{array}{l}0.20(0.10) \\
0.18(0.12) \\
0.00(0.004) \\
-0.02(0.11) \\
-0.02(0.09)\end{array}$ & $\begin{array}{l}0.05^{*} \\
0.13 \\
0.89 \\
0.88 \\
0.82\end{array}$ & 0.07 \\
\hline Family-related pros/advantages of GT & $\begin{array}{l}\text { Ethnic affirmation } \\
\text { Age } \\
\text { Family history of breast/ovarian cancer } \\
\quad \text { Yes vs. no } \\
\text { Personal history of breast/ovarian cancer } \\
\quad \text { Yes vs. no }\end{array}$ & $\begin{array}{r}0.28(0.10) \\
0.00(0.00) \\
-0.10(0.12) \\
0.04(0.10)\end{array}$ & $\begin{array}{l}0.007^{*} \\
0.90 \\
0.41 \\
0.69\end{array}$ & 0.07 \\
\hline Cons/disadvantages of GT & $\begin{array}{l}\text { Ethnic search } \\
\text { Age } \\
\text { Family history of breast/ovarian cancer } \\
\quad \text { Yes vs. no } \\
\text { Personal history of breast/ovarian cancer } \\
\text { Yes vs. no }\end{array}$ & $\begin{array}{l}0.14(0.07) \\
0.005(0.004) \\
0.05(0.10) \\
-0.07(0.08)\end{array}$ & $\begin{array}{l}0.04^{*} \\
0.24 \\
0.61 \\
0.41\end{array}$ & 0.05 \\
\hline Family-related cons/disadvantages of GT & $\begin{array}{l}\text { Ethnic search } \\
\text { Age } \\
\text { Family history of breast/ovarian cancer } \\
\quad \text { Yes vs. no } \\
\text { Personal history of breast/ovarian cancer } \\
\quad \text { Yes vs. no }\end{array}$ & $\begin{array}{r}0.05(0.14) \\
-0.09(0.13)\end{array}$ & $\begin{array}{l}0.02^{*} \\
0.73 \\
0.72 \\
0.48\end{array}$ & 0.06 \\
\hline Stigma associated with GT & $\begin{array}{l}\text { Other-group orientation } \\
\text { Age } \\
\text { Family history of breast/ovarian cancer } \\
\quad \text { Yes vs. no } \\
\text { Personal history of breast/ovarian cancer } \\
\text { Yes vs. no }\end{array}$ & $\begin{array}{l}-0.28(0.12) \\
0.01(0.005) \\
0.02(0.12) \\
-0.06(0.11)\end{array}$ & $\begin{array}{l}0.03^{*} \\
0.07 \\
0.85 \\
0.61\end{array}$ & 0.06 \\
\hline Confidentiality concerns related to GT & $\begin{array}{l}\text { Ethnic affirmation } \\
\text { Centrality } \\
\text { Income } \\
\quad \leq \text { USD } 19,999 / \mathrm{yr} \text { vs. } \geq \text { USD 20,000/yr } \\
\text { Age } \\
\text { Family history of breast/ovarian cancer } \\
\quad \text { Yes vs. no } \\
\text { Personal history of breast/ovarian cancer } \\
\quad \text { Yes vs. no }\end{array}$ & $\begin{array}{r}-0.52(0.17) \\
0.34(0.14) \\
-0.42(0.15) \\
0.004(0.01) \\
0.23(0.17) \\
0.32(0.15)\end{array}$ & $\begin{array}{l}0.002^{*} \\
0.01^{*} \\
0.008^{*} \\
0.57 \\
0.19 \\
0.03^{*}\end{array}$ & 0.16 \\
\hline Concerns about abuses of GT & $\begin{array}{l}\text { Other-group orientation } \\
\text { Age } \\
\text { Family history of breast/ovarian cancer } \\
\quad \text { Yes vs. no } \\
\text { Personal history of breast/ovarian cancer } \\
\quad \text { Yes vs. no }\end{array}$ & $\begin{array}{r}-0.29(0.12) \\
0.09(0.05) \\
-0.07(0.12) \\
-0.003(0.10)\end{array}$ & $\begin{array}{l}0.02^{*} \\
0.06\end{array}$ & 0.07 \\
\hline
\end{tabular}

* Significance level $\mathrm{p} \leq 0.05$. Final multivariate models include variables significant from forward selection procedure plus confounders and any theoretically necessary covariates (age, family and personal history of breast/ovarian cancer). 
A primary strength of this study lies in its inclusion of a group of complex, yet interrelated ethnic, racial and cultural identity factors, which allowed examination of their combined influence on perceived benefits and barriers to genetic testing for cancer risk. While a few previous studies have begun to examine culturally informed attitudes about genetic testing in women of African descent, including associations with medical mistrust as well as nativity $[15,26]$, to our knowledge, this is the first study to examine ethnic, racial and cultural identity as they relate to beliefs and attitudes about genetic testing. As described earlier, this research builds upon the evolving field of multicultural genetic counseling and transitions away from the assessment of traditionally visible racial and cultural groups to understand a more fully integrated cognitive-affective racial and cultural identity. From this multicultural perspective, greater consideration is given to the range of variation among racial and cultural groups [30]. In fact, a review of existing literature related to genetic counseling by Wang [30] found that only $9 \%$ of articles discussed cultural issues; meanwhile, amongst those few who did, 75\% considered a cross-cultural, group-specific approach rather than one which values understanding variation among group members. The study results presented here, which treat ethnic, racial and cultural identity as distinct, but closely related constructs, thus, uniquely add to the multicultural counseling literature by following the shift from exploring race alone to understanding the impact of ethnic, racial and cultural identities [30, 36, 39].

Although ethnic identity has been well understood and examined widely by psychologists as an important multicultural construct $[36,49]$ related to overall psychological well-being [50], to date, ethnic identity has been largely overlooked in terms of its relationship to other health-related outcomes [51-53]. In one study, adolescent AfricanAmerican males with high ethnic identity scores had lower mean blood pressures compared to those with low scores [54]. However, in the cancer prevention realm, a recent review examining the use of sociocultural constructs in cancer-screening research among African Americans determined that there has been no clear link found between ethnic identity and health behaviors to date; therefore, further work is needed [32]. To our knowledge, thus far, there have been only 2 studies examining ethnic identity as it relates to cancer prevention outcomes $[53,55]$. In the first [55], the self-chosen racial pride label of 'African American' versus 'Black' was found to be the only predictor of mammography screening for African-American women, with women who self-identified as 'African American' being more likely to report intentions to obtain a mammo- gram. Results suggest that women who self-label with a more ethnic, cultural 'African American' may feel less defined by or at odds with a racial infused dominant culture, compared to women who identify with a more racial, other-defined imposed label of 'Black'. In the second known study in this area [53], 113 African-American women were assessed as they underwent breast cancer risk counseling, and predictors of risk and worry changes as a result of this counseling were evaluated. Women with higher levels of societal identity related to the Black or African-American community were found to have larger reductions in perceived risk and cancer worry, highlighting the role of psychosocial counseling interventions for women of African descent as they learn to cope with breast cancer risk [53].

The results of our study further underscore the role of ethnic identity as a psychosocial factor which warrants consideration in shaping women's perceptions of genetic testing for cancer risk. Specifically, study results suggest that having a positive ethnic identity may be associated with having a positive influence on perceived benefits about genetic testing among women of African descent, as demonstrated by the findings of total MEIM score, ethnic affirmation and other-group orientation. Howev$\mathrm{er}$, as a possible negative influence, women with higher ethnic search scores reported both more cons/disadvantages and family-related cons/disadvantages related to genetic testing. Considered in light of previous literature, it is possible that ethnic search may behave similarly to the immersion/emersion stage of Cross' Nigrescence Theory of racial identity, in which an individual searches for ways to be comfortable with his/her identity, becoming deeply ingrained in 'becoming Black', and there is initially a strong, if not highly emotionally charged in-group membership $[56,57]$. This transitional stage has previously been associated with a range of negative health outcomes in African Americans including low self-esteem, personal distress and elevated blood pressure $[14,56,58]$. Considered in this context, the negative association of ethnic search to both cons and family-related cons associated with genetic testing may not be all that surprising. Ultimately, even though this analysis included a select sample of women who had already agreed to participate in a study offering free genetic counseling, our results highlight critical ethnic identity factors which may influence benefits and barriers to genetic testing among at-risk women of African descent. These findings are critical given previous research suggesting that perceived benefits and barriers may impact uptake of genetic counseling and testing in African Americans [14], warranting consideration by genetic counselors and educators. 
Racial and cultural identity, although related closely to ethnic identity, allow for the study of identity as a result of minority status with a specific focus on potential discriminatory treatment as well as consideration of Afro-specific racial and cultural influences [36]. A wealth of previous research has focused on psychological aspects of African-American identity [34], including associations with self-esteem [59] and academic performance [60]. Yet, there is no clear consensus among psychological identity theorists over whether strong identification with racial group places individuals of African descent at risk for adverse effects or whether such identification serves as a protective factor which promotes resiliency against racism and discrimination [34, 61-63]. In the case of the results presented here, a strong racial identity (individuals with higher centrality scores) was associated with higher confidentiality concerns related to genetic testing in multivariate analyses, controlling for relevant factors. This finding may not be surprising in light of research conducted among African Americans which has found a positive relationship between medical mistrust and concerns about abuses of genetic testing [15] as well as the larger body of research discussed above linking specific stages of racial identity to negative health outcomes [56-58]. Further, as the centrality items may be more closely tied to an individual's sense of self and esteem, in comparison to the other identity measures evaluated here which may incorporate more focus on group membership, it would make intuitive sense that centrality would be closely aligned with any invasion of this private self (i.e. confidentiality concerns). Given that concerns about confidentiality may inhibit an individual with regard to considering or seeking out genetic counseling and testing $[11,63,64]$, it is possible that having a strong racial identity (as measured by higher centrality) may have a potentially detrimental effect on uptake of genetic testing among at-risk women of African descent. However, the potential effect of our results in determining uptake is very limited in this, given the highly select sample of women in this analysis had already agreed to participate in the research which included the opportunity for free genetic counseling. One could argue such interest was artificially high due to these services being free. Meanwhile, although Africentrism may be considered an important aspect in terms of cultural identity with previous effects found on alcohol initiation and consumption [65], drug use and related attitudes [66], and rebelliousness [50], in this study, this specific measure had no influence on perceived benefits or barriers to genetic testing.

Identity and $B R C A$ Genetic Testing among Women of African Descent
Given substantial disparities evident in the uptake of $B R C A$ genetic counseling and testing services among women of African descent [3-8], research that identifies cultural influences on perceived benefits and barriers to genetic testing is important if we are to develop truly culturally competent care. While a few studies have begun to examine such cultural influences within and among African Americans [15], it is imperative that researchers consider the possible range of culturally-specific variations and heterogeneity of experience among individuals of African descent [22-25]. Research conducted by members of our team has attempted to understand such heterogeneity in the area of genetic testing for cancer risk, finding associations between cultural factors such as medical mistrust [15], as described above, and for nativity [26]. In Sussner et al. [26], being foreign born was a significant predictor of anticipated negative emotional reactions about genetic testing $(\beta=0.26$; $\mathrm{SE}=0.11$; $\mathrm{p}=$ $0.01)$. Further, in that prior study, breast cancer-specific distress scores (avoidance symptoms) were positively related to anticipated negative emotional reactions, confidentiality concerns and family-related guilt associated with genetic testing. Considered in light of findings presented here, this research emphasizes the need to better understand such cultural specificity among individuals of African descent to not only avoid potential stereotyping and inaccurate generalizations across broad categories of people [24], but moreover better inform the design, development and implementation of much needed culturally-sensitive interventions which address the perceived benefits and barriers related to genetic services among diverse women of African descent [8, 18, 20, 21]. Specifically, such culturally-based interventions which are grounded in a greater understanding of how cultural background may influence beliefs, attitudes and reactions to genetic services will ultimately influence the design of more culturally-sensitive protocols $[8,26]$ that not only consider group-specific beliefs, but incorporate individual variation and the range of perceptions held by individuals of African descent. For example, given study findings, it may be important to design interventions which target women of African descent with high ethnic search and racial identity (centrality) scores to counter possible negative beliefs they may experience about genetic testing. At the same time, it may be useful to develop interventions which foster a strong sense of ethnic identity in other individuals of African descent due to the association found here with positive beliefs and attitudes about genetic testing. Ultimately, genetic counselors may be able to use this information to ensure that decisions

Public Health Genomics 2011;14:356-370 
related to genetic testing for cancer risk are fully informed and culturally appropriate within women of African descent.

\section{Study Limitations}

There are severallimitations of the study which should be noted. First, there were some variables with missing data, resulting in smaller sample sizes where individuals with missing data were deleted from analyses. Second, since this study examined women who were participating in a larger longitudinal study which offered free genetic counseling (which the majority accepted), this highly selected sample may be biased by the decision of these high-risk women to participate in the larger study, some of whom may have been predisposed to be responsive to genetic counseling/testing. In other words, those least interested in genetic counseling would have never agreed to participate in the study. Unfortunately, it is not possible to determine if any of the predictors correlated with uptake of genetic counseling or testing. Specifically, there is no actual way of knowing what the true denominator was (those not interested) for potential participants in the larger longitudinal study due to the nature of the recruitment via physician referral and community outreach. Future research should thus explore the uptake of genetic counseling and testing as behavioral outcomes. Third, and related to the above, the generalizability of study results and ability to make inferences about the larger population is limited given this highly select sample. Generalizability is also limited as study results may not be applicable to other racial/ethnic groups beyond women of African descent and only relevant to similarly diverse, metropolitan samples in the U.S. which include similarly representative samples of individuals of African descent. Fourth, given the sample consisted of mostly middle-class educated and insured women of African descent, it is likely that these women did not face the same access-related barriers which other individuals from this population group may experience in relation to obtaining genetic services. In fact, research with women of African descent shows that cost of genetic services is one of the most influential factors inhibiting decision to receive genetic services [19]. Fifth, as research underscores the value of examining perceived benefits and barriers to genetic counseling separate from those of testing [14], this study is limited as it only assessed pros and cons related to genetic testing and thus may not be applied directly to counseling. Sixth, while these results are suggestive of an association between ethnic and racial identity, and beliefs and attitudes about genetic testing, such findings cannot determine direction of causation. Related to this point, the predictive value of several of the final multivariate models may be small, given the relatively low coefficient of determination, although this may be of secondary importance since the regression is not being used to make predictions per se. Seventh, given our limited understanding of how ethnic, racial and cultural identity may differentially influence beliefs and attitudes about genetic testing, it is suggested that future research address these complex relationships through open-based, qualitative studies. Finally, although we found no significant associations between any of the selfidentified racial/ethnic identity categories (Black/African American, Black-West Indian/Caribbean and BlackOther) with perceived benefits and barriers to genetic testing, we acknowledge that future research with larger sample sizes may wish to explore this possible association and examine how self-identified race/ethnicity categories maps onto ethnic, racial and cultural identity and in turn influences beliefs about genetic testing. For example, our previously published cross-sectional secondary analysis of the same dataset found important acculturation-related differences (US vs. foreign born) that influenced perceived barriers to genetic testing among women of African descent [26].

\section{Conclusions and Implications for Practice}

Study results contribute to the literature by identifying critical ethnic, racial and cultural identity factors that may influence perceived benefits and barriers to genetic testing for breast and ovarian cancer among at-risk women of African descent. Specifically, findings related to ethnic and racial identity may help inform the development of more culturally-sensitive protocols which more adequately meet the needs of this heteregenous population.

\section{Acknowledgements}

Data analyzed in this study comes from research funded by the American Cancer Society (TURGS 02-246-01) and the U.S. Army Medical Research and Material Command (DAMD17-011-0334). Dr. Sussner's work was supported through the National Cancer Institute Training Grant (R25 CA81137). 


\section{References}

$\checkmark 1$ Chen S, Parmigiani G: Meta-analysis of $B R C A 1$ and $B R C A 2$ penetrance. J Clin Oncol 2007;25:1329-1333.

$\checkmark 2$ Kinney AY, Croyle RT, Dudley WN, Bailey CN, Pelias MK, Neuhausen SL: Knowledge, attitudes and interest in breast-ovarian cancer gene testing: a survey of a large AfricanAmerican kindred with a BRCA1 mutation. Prev Med 2001;33:543-551.

$\checkmark 3$ Hall MJ, Olopade OI: Confronting genetic testing disparities: knowledge is power. JAMA 2005;293:1783-1785.

$\checkmark 4$ Hall MJ, Olopade OI: Disparities in genetic testing: thinking outside the BRCA box. J Clin Oncol 2005;24:2197-2203.

5 Olopade OI: Genetics in clinical cancer care: a promise unfulfilled among minority populations. Cancer Epidemiol Biomarkers Prev 2004;13:1683-1686.

-6 Armstrong K, Micco E, Carney A, Stopfer J, Putt M: Racial differences in the use of $B R C A 1 / 2$ testing among women with a family history of breast or ovarian cancer. JAMA 2005;293:1729-1736.

$\checkmark 7$ Matthews AK, Cummings S, Thompson S, Wohl V, List M, Olopade OI: Genetic testing of African Americans for susceptibility to inherited cancers: use of focus groups to determine factors contributing to participation. J Psychosoc Oncol 2000;18:1-19.

$>8$ Lerman C, Hughes C, Benkendorf JL, Biesecker B, Kerner J, Willison J, Eads N, Hadley D, Lynch J: Racial differences in testing motivation and psychological distress following pretest education for BRCA1 gene testing. Cancer Epidemiol Biomarkers Prev 1999;8: 361-367.

9 Simon MS, Korczak JF, Yee CL, Malone KE, Ursin G, Bernstein L, McDonald JA, Deapen D, Strom BL, Press MF, Marchbanks PA, Burkman RT, Weiss IK, Schwartz AG: Breast cancer risk estimates for relatives of white and African American women with breast cancer in the Women's Contraceptive and Reproductive Experiences Study. J Clin Oncol 2006;24:2498-2504.

10 Simon MS, Petrucelli N: Hereditary breast and ovarian cancer syndrome. The impact of race on uptake of genetic counseling and testing; in Verma M (ed): Methods in Molecular Biology, Cancer Epidemiology. New York, Springer, 2009, vol 471, pp 487-500.

$\checkmark 11$ Donovan KA, Tucker DC: Knowledge about genetic risk for breast cancer and perceptions of genetic testing in a sociodemographically diverse sample. J Behav Med 2000;23: 15-36.

- 12 Peters N, Domchek SM, Rose A, Polis R, Stopfer J, Armstrong K: Knowledge, attitudes, and utilization of BRCA1/2 testing among women with early-onset breast can cer. Genet Test 2005;9:48-53.
13 Hughes C, Gomez-Caminero A, Benkendorf J, Kerner J, Isaacs C, Barter J, et al: Ethnic differences in knowledge and attitudes about $B R C A 1$ testing in women at increased risk. Patient Educ Couns 1997;32:51-62.

14 Thompson H, Valdimarsdottir HB, DuteauBuck C, Guevarra J, Bovbjerg DH, Richmond-Avellaneda C, Amarel D, Godfrey D, Brown K, Offit K: Psychosocial predictors of $B R C A$ counseling and testing decisions among urban African-American women. Cancer Epidemiol Biomarkers Prev 2002;11: 1579-1585.

15 Thompson HS, Valdimarsdottir HB, Jandorf L, Redd W: Perceived disadvantages and concerns about abuses of genetic testing for cancer risk: differences across African American, Latina and Caucasian women. Patient Educ Couns 2003;51:217-227.

16 Bowman JE: Technical, genetic, and ethnical issues in screening and testing of AfricanAmericans for hemochromatosis. Genet Test 2000;4:207-212.

17 Telfair J, Nash NB: African American culture; in Fisher NL (ed): Cultural and Ethnic Diversity: A Guide for Genetics Professionals. Baltimore, The Johns Hopkins University Press, 2000, pp 37-59.

18 Peters N, Rose A, Armstrong K: The association between race and attitudes about predictive genetic testing. Cancer Epidemiol Biomarkers Prev 2004;13:361-365.

19 Ford ME, Alford SH, Britton D, McClary B, Gordon HS: Factors influencing perceptions of breast cancer genetic counseling among women in an urban health care system. J Genet Couns 2007;16:735-753.

20 Charles S, Kessler L, Stopfer JE, Domchek S, Halbert $\mathrm{CH}$ : Satisfaction with genetic counseling for BRCA1 and BRCA2 mutations among African American women. Patient Educ Couns 2006;63:196-204.

21 Baty BJ, Kinney AY, Ellis SM: Developing culturally sensitive cancer genetics communication aids for African Americans. Am J Med Genet A 2003;118A:146-155.

22 Guidry JJ, Matthews-Juarez P, Copeland, VA: Barriers to breast cancer control for African-American women: the interdependence of culture and psychosocial issues. Cancer 2003;97(suppl 1):318-323.

23 Kudadjie-Gyamfi E, Consedine NS, Magai $\mathrm{C}$ : On the importance of being ethnic: coping with the threat of prostate cancer in relation to prostate cancer screening. Cultur Divers Ethnic Minor Psychol 2006;12:509-526.

24 Magai C, Consedine NS, Conway F, Neugut A, Culver C: Diversity matters: unique populations of women and breast cancer screening. Cancer 2004;100:2300-2307.

25 Consedine NS, Magai C, Krivoshekova YS, Ryzewicz L, Neugut AI: Fear, anxiety, worry, and breast cancer screening behavior: a critical review. Cancer Epidemiol Biomarkers Prev 2004; 13:501-510.
26 Sussner KM, Thompson HS, Valdimarsdottir H, Redd WH, Jandorf L: Acculturation and familiarity with attitudes toward and beliefs about genetic testing for cancer risk within Latinas in East Harlem, New York City. J Genet Couns 2009;18:60-71.

27 Edwards TA, Thompson HS, Kwate NO, Brown K, McGovern MM, Forman A, KapilPair N, Jandorf L, Bovbjerg DH, Valdimarsdottir HB: Association between temporal orientation and attitudes about BRCA1/2 testing among women of African descent with family histories of breast cancer. Patient Educ Couns 2008;72:276-282.

28 Thompson HS, Valdimarsdottir HB, Winkel G, Jandorf L, Redd W: The Group-Based Medical Mistrust Scale: psychometric properties and association with breast cancer screening. Prev Med 2004;38:209-218.

$>29$ Hughes C, Fasaye GA, LaSalle VH, Finch C: Sociocultural influences on participation in genetic risk assessment and testing among African American women. Patient Educ Couns 2003;51:107-114.

30 Wang VO: Multicultural genetic counseling: then, now and in the 21st century. Am J Med Genet 2001;106:208-215.

31 Betancourt H, Lopez S: The study of culture, ethnicity, and race in American Psychology; in Peplau LA, Taylor SE (eds): Sociocultural Perspectives in Social Psychology: Current Readings. Upper Saddle River, Prentice Hall, 1997.

32 Deshpande AD, Thompson VL, Vaughn KP, Kreuter MW: The use of sociocultural constructs in cancer screening research among African Americans. Cancer Control 2009; $16: 256-263$

33 Stryker S, Serpe RT: Identity salience and psychological centrality: equivalent, overlapping or complementary concepts? Soc Psychol Quart 1994;57:16-36.

34 Sellers RM, Rowley SA, Chavous TM, Shelton JN, Smith MA: Multidimensional Inventory of Black Identity: a preliminary investigation of reliability and construct validity. J Pers Soc Psychol 1997;73:805-815.

$>35$ Phinney JS: The Multigroup Ethnic Identity Measure: a new scale for use with diverse groups. J Adolescent Res 1992;7:156-176.

$>36$ Cokley KO: Racial(ized) identity, ethnic identity, and Afrocentric values: conceptual and methodological challenges in understanding African American identity. J Couns Psychol 2005;52:517-526.

37 Cornell S, Hartmann D: Ethnicity and Race: Making Identities in a Changing World. Thousand Oaks, Pine Forge Press, 2007.

38 Carter RT, Quereshi A: A typology of philosophical assumptions in multicultural counseling and training; in Ponterroto JG, Casas JM, Suzuki LA, Alexander CM (eds): Handbook of Multicultural Counseling. Thousand Oaks, Sage Publications, 1995, pp 239262 . 
39 Parham TA: Counseling Persons of African Descent: Raising the Bar of Practitioner Competence. Thousand Oaks, Sage Publications, 2002.

40 Grills C, Longshore D: Africentrism: psychometric analyses of a self-report measure. J Black Psychol 1996;22:86-106.

41 New York City Department of City Planning Population Division: The Newest New Yorkers 2000, Immigrant New York in the New Millennium, NYC DCP \#04-10. New York, NYC Dept of City Planning, 2004.

42 Parmigiani G, Berry DA, Aquilar O: Determining carrier probabilities for breast cancer susceptibility genes BRCA1 and BRCA2. Am J Hum Genet 1998;62:145-158.

43 Frank TS, Manley SA, Olopade OI, Cummings S, Garber JE, Bernhardt B, Antman K, Russo D, Wood ME, Mullineau L, Isaacs C, Peshkin B, Buys S, Venne V, Rowley PT, Loader S, Offit K, Robson M, Hampel H, Brener D, Winer EP, Clark S, Weber B, Strong LC, Thomas A, et al: Sequence analysis of $B R C A 1$ and BRCA2: correlation of mutations with family history and ovarian cancer risk. J Clin Oncol 1998;16:2417-2425.

44 Couch FJ, DeShano ML, Blackwood MA, Calzone K, Stopfer J, Campeau L, Ganguly A, Rebbeck T, Weber BL: BRCA1 mutations in women attending clinics that evaluate the risk of breast cancer. N Engl J Med 1997;336: 1409-1415.

$\checkmark 4$ Jacobsen PB, Valdimarsdottir HB, Brown KL, Offit K: Decision-making about genetic testing among women at familial risk for breast cancer. Psychosom Med 1997;59:459466.

46 Hughes C, Lerman C, Lustbader E: Ethnic differences in risk perception among women at increased risk for breast cancer. Breast Cancer Res Treat 1996;40:25-35.
47 Lipkus IM, Iden D, Terrenoire J, Feaganes JR: Relationships among breast cancer concern, risk perceptions, and interest in genetic testing for breast cancer susceptibility among African American women with and without a family history of breast cancer. Cancer Epidemiol Biomarkers Prev 1999;8:533-539.

48 Halbert C, Kessler L, Stopfer JE, Domchek S, Wileyto EP: Low rates of acceptance of BRCA1 and BRCA2 test results among African American women at increased risk for hereditary breast-ovarian cancer. Genet Med 2006;8:576-582.

49 Phinney JS: Ethnic identity in adolescents and adults: review of research. Psychol Bull 1990;108:499-514.

50 Brook JS, Pahl K: The protective role of ethnic and racial identity and aspects of an Africentric orientation against drug use among African American young adults. J Genet Psychol 2005; 166:329-345.

51 Helms JE: Black and White Racial Identity: Theory, Research and Practice. Westport Greenwood Press, 1990.

52 Landrine H, Klonoff E: The African American acculturation scale: origin and current status; in Jones RL (ed): Handbook of Tests and Measurements for Black Populations. Hampton, Cobb and Henry Publishers, 1996.

53 Bowen DJ, Christensen CL, Powers D, Graves DR, Anderson CA: Effects of counseling and ethnic identity on perceived risk and cancer worry in African American women. J Clin Psychol Med S 1998;5:365-379.

54 Scribner R, Hohn A, Dwyer J: Blood pressure and self-concept among African-American adolescents. J Natl Med Assoc 1995;87:417422.

55 Bowen D, Hickman KM, Powers D: Importance of psychological variables in understanding risk perceptiosn and breast cancer screening of African American women. Womens Health 1997;3:227-242.

56 Parham TA, Helms JE: Attitudes of racial identity and self-esteem of Black students: an exploratory study. J Coll St Personnel 1985a;26:143-147.
57 Cross WE Jr: Shades of Black: Diversity in African-American Identity. Philadelphia, Temple University Press, 1991.

58 Parham TA, Helms JE: Relation of racial identity attitudes to self-actualization and affective states of Black students. J Couns Psychol 1985b;32:431-440.

59 Rowley SJ, Sellers RM, Chavous TM, Smith MA: The relationship between racial identity and self-esteem in African American college and high school students. J Pers Soc Psychol 1998;74:715-724.

60 Taylor RD, Casten R, Flickinger SM, Roberts D, Fulmore CD: Explaining the school performance of African American adolescents. J Res Adolescence 1994;4:21-44.

61 Azibo D: Liberation Psychology. Trenton, African World Press, 1992.

62 Miller DB: Racial socialization and racial identity: can they promote resiliency for African American adolescents? Adolescence 1999; 135:493-501.

63 Rose AL, Peters N, Shea JA, Armstrong K: Attitudes and misconceptions about predictive genetic testing for cancer risk: a focus group study. Community Genet 2005;8:145151.

64 Catz DS, Green NS, Tobin JN, Lloyd-Puryear MA, Kyler P, Umemoto A, Cernoch J, Browne $\mathrm{R}$, Wolman F: Attitudes about genetics in underserved, culturally diverse populations. Community Genet 2005;8:161-172.

65 Nasim A, Belgrave FZ, Jagers RJ, Wilson KD, Owens K: The moderating effects of culture on peer deviance and alcohol use among high-risk African-American adolescents. J Drug Educ 2007;37:335-363.

-66 Belgrave FZ, Van Oss Marin B, Chambers DB: Cultural, contextual and intrapersonal predictors of risky sexual attitudes among urban African American girls in early adolescence. Cultur Divers Ethnic Minor Psychol 2000;6:309-322. 